\title{
Processamento de estruturas coordenadas com elipse no Português Brasileiro
}

\author{
Processing coordinate structures with ellipsis in Brazilian Portuguese \\ Andressa Christine Oliveira da Silva \\ Aline Alves Fonseca \\ Laís Lagreca de Carvalho \\ Universidade Federal de Juiz de Fora, Juiz de Fora, MG, Brasil
}

$\diamond$

Resumo: Este trabalho investiga o processamento de dois tipos de sentenças coordenadas: (1) estrutura coordenada de objeto (nongapping), Alice assou bolos pras amigas e biscoitos pra sua prima; e (2) estrutura coordenada de sujeito (gapping), Alice assou bolos pras amigas e Camila pra sua prima. Conduzimos três testes: um questionário em que os participantes ranqueavam suas preferências de completação da oração principal "Alice assou bolos para as amigas e...", e dois testes de self-paced reading em que medimos o tempo de reação à leitura do DP que aparece depois da conjunção "e" e do PP que segue o DP e desfaz uma possível ambiguidade. Esta pesquisa foi inspirada pelos trabalhos de Carlson $(2001,2002)$, que investigou o processamento dessas estruturas no inglês. Os resultados dos três experimentos sugerem que nem sempre a construção mais simples do ponto de vista estrutural (nongapping) é o input mais simples para o parser.

Palavras-chave: Elipse; Coordenada; Processamento de sentenças; Psicolinguística; Português brasileiro

\begin{abstract}
This paper investigates the sentence processing of two types of coordinate sentences in Brazilian Portuguese: (1) coordinate structure with conjoined objects (nongapping), like Alice baked cakes for her friends and cookies for her cousin; and (2) coordinate structure with VP ellipsis (gapping), like Alice baked cakes for friends and Camila for her cousin. Three experiments were carried out, a written questionnaire in which subjects ranked their preferences for completing the main sentence, such as in "Alice baked cakes for her friends and ..."; and two self-paced reading tasks in which we measured the reaction time to read the DP following the conjunction "and" and the PP that follows the DP and undoes a possible ambiguity. This research is based on the works of Carlson $(2001,2002)$, who investigated the processing of these structures in American English. The results of the three experiments indicate that a simpler syntactic structure (the nongapping) is not always the easiest input for the parser to process.
\end{abstract}

Keywords: Ellipsis; Coordinate clauses; Sentence processing; Psycholinguistics; Brazilian Portuguese 


\section{Introdução}

O presente trabalho tem como tema o processamento de sentenças, na perspectiva psicolinguística, de estruturas coordenadas com elipses do Português Brasileiro (doravante $\mathrm{PB}$ ). Há vários tipos de construções elípticas no $\mathrm{PB}$, no entanto, esta pesquisa pretende trabalhar apenas com o tipo gapping, também conhecida como elipse lacunar (MILHORANCE, 2014), que ocorre em estruturas coordenadas. A estrutura gapping caracterizase por ser um processo sintático opcional que consiste em elidir o material linguístico da segunda oração de uma estrutura coordenada (CARLSON, 2001), o qual costuma ser idêntico ao material linguístico da primeira oração, sendo elidido o verbo e, em alguns casos, tanto o verbo quanto o objeto. Esta pesquisa foi inspirada nos trabalhos de Carlson $(2001,2002)$ que investigou estruturas gapping e nongapping no inglês americano, como em:

(1) Alice bakes cakes for tourists and Caroline for her family.

(2) Alice bakes cakes for tourists and brownies for her family.

A estrutura (1), chamada de gapping, possui a elipse do VP completo na segunda oração [bakes cakes] e os DPs que ocupam a posição de sujeito das orações, [Alice] e [Caroline], compartilham características semânticas de [+nome próprio], [+feminino] e [+singular], configurando um paralelismo semântico. Já a estrutura (2), apresenta a coordenação entre objetos dentro do VP [bakes cakes ... and brownies...], por isso essas estruturas são chamadas de nongapping. No entanto, para que sejam mais bem aceitas gramaticalmente, os DPs que estão na posição de objetos coordenados devem compartilhar características que validem a regência verbal do VP, ou seja, devem apresentar algum grau de paralelismo semântico. Assim torna-se possível recuperar o DP sujeito e o verbo da oração principal como nós dominantes do DP que aparece depois da conjunção "and" na estrutura. De acordo com os princípios de Minimal Attachment e Late Closure, previstos dentro da Teoria Garden-Path (FRAZIER \& FODOR, 1978; FRAZIER, 1979), as coordenadas de objeto, como em (2), seriam estruturas mais simples e, portanto, mais fáceis de serem processadas pelo parser se comparadas às estruturas de elipse do VP, como em (1).

Por outro lado, Carlson (2002) propõe a Hipótese do Paralelismo do DP, que diz:

O processador favorece análises nas quais os DPs compartilham propriedades internas (possuem traços sintáticos, prosódicos e semânticos similares); compartilham propriedades externas (aparecem em posições estruturais similares dentro de suas respectivas orações ou sintagmas) e vice-versa. (CARLSON, 2002, p. 6) ${ }^{1}$

De acordo com essa hipótese, as características semânticas [+nome próprio], $[+$ feminino $]$ e $[+$ singular $]$, compartilhadas pelos DPs [Alice] e [Caroline] na estrutura (1), favorecem o processamento do segundo DP [Caroline] como sujeito do VP elíptico [bakes cakes] da segunda oração.

Tais estruturas são encontradas também no Português Brasileiro (PB), como em:

(3) Alice assou bolos para as amigas e Carolina para sua família.

(4) Alice assou bolos para as amigas e biscoitos para sua família.

Temos por objetivo investigar se os princípios Minimal Attachment e Late Closure se aplicam no processamento destas estruturas coordenadas elípticas no PB e se há efeitos do paralelismo semântico entre DPs, como previsto pela Hipótese do Paralelismo dos DPs, de Carlson (2002). Para isso, aplicamos 3 tarefas experimentais, uma tarefa off-line de ranqueamento de completações e duas tarefas on-line de self-paced reading, com 70 falantes adultos do $\mathrm{PB}$, todos estudantes universitários da $\mathrm{UFJF}^{2}$.

A seguir, apresentaremos uma breve revisão do quadro teórico relevante para o desenvolvimento deste estudo, a metodologia de aplicação dos testes e as análises qualitativas e quantitativas dos resultados encontrados e uma breve discussão sobre os desdobramentos desses resultados dentro da perspectiva da teoria psicolinguística de processamento de frases.

\section{Aporte Teórico}

Iniciamos esta seção apresentando brevemente a Teoria Garden-Path (TGP), proposta por Frazier e Fodor (1978) e Frazier (1979). O modelo de processamento proposto por Frazier e Fodor (1978) é dividido em dois estágios: o primeiro estágio, chamado pelas autoras de PPP (Preliminary Phrase Packager) consiste na atribuição de nós lexicais e frasais a grupos de palavras do input que é recebido pelo parser. O segundo estágio é chamado de SSS (Sentence Structure Supervisor) e faz

\footnotetext{
1 Todas as traduções apresentadas neste artigo são de responsabilidade das autoras.

2 Todas as tarefas experimentais desta pesquisa estão cobertas pelo CAAE 26935114.8.0000.5147, aprovado pelo Comitê de Ética da UFJF. Todos os participantes são voluntários e assinaram o Termo de Consentimento Livre e Esclarecido (TCLE).
} 
o papel de organizar o material "empacotado" pelo PPP em marcadores frasais completos, através da estipulação de nós não terminais mais altos. A evidência principal para se justificar dois estágios de processamento se deve à limitação da memória de trabalho. Segundo as autoras, a memória de trabalho não suportaria a análise de cadeias maiores, enquanto que em um modelo que assume haver um processo preliminar seguido de um outro, que o supervisiona, a memória de trabalho é esvaziada quando a cadeia é passada para o segundo estágio de processamento.

Além do modelo de processamento em dois estágios proposto pelas autoras, Frazier (1979) propõe dois princípios que regem o processamento serial do input linguístico, que são:

Minimal Attachment (Aposição Mínima): Aponha o material de entrada no sintagma que estiver sendo construído, usando a menor quantidade de nós sintáticos consistentes com as regras de boa formação da gramática (FRAZIER, 1979, p. 24).

Late Closure (Encerramento Tardio): "Quando possível, aponha o material de entrada na oração ou sintagma que estiver sendo processado (FRAZIER, 1979, p. 33)

Os dois princípios básicos citados acima estão dentro do PPP e geram estruturas iniciais que são, então, remetidas e "supervisionadas" pelo SSS que irá gerar a estrutura sintática final para a sentença. O processador de dois estágios faz a análise serial da cadeia como se não houvesse ambiguidade, ou seja, ele escolhe uma estrutura, aplicando os princípios de Minimal Attachment e Late Closure, e segue até o fim do processamento. Caso a sentença apresente uma ambiguidade que viole um dos princípios, será necessário que haja reanálise, e, dependendo dos processos envolvidos, a reanálise será menos ou mais custosa para o processador.

Maia (2013) traz uma revisão de trabalhos no PB que investigam a aplicação dos princípios de Minimal Attachment, principalmente, e Late Closure da TGP em experimentos on-line (leitura automonitorada, escuta automonitorada e rastreamento ocular) e off-line (questionário). Essas pesquisas foram realizadas no Laboratório de Psicolinguística Experimental (LAPEX / UFRJ) e, uma delas, foi feita em parceria com a UEZO / RJ. O autor dá destaque a três trabalhos: o primeiro deles busca, através de atividades off-line e on-line, identificar a preferência de interpretação de PPs ambíguos, que podem ser apostos como adjunto adverbial ou adjunto adnominal, como em: $O$ menino viu o turista com o binóculo; o segundo trabalho traz resultados de experimentos com técnicas on-line que avaliaram o processamento de sentenças contendo PPs com função de adjunto ou de argumento do verbo, que admitem aposição sintática ambígua ao sintagma verbal ou ao sintagma nominal objeto, como em: $O$ redator escreveu o manual para o professor para o editor da nova série; o terceiro trabalho analisa a leitura de frases que apresentam uma palavra ambígua que pode ser interpretada como nome ou verbo na $3^{a}$ pessoa do singular presente do indicativo, como em: Mãe suspeita de assassinato do filho foge da delegacia. Os resultados das três pesquisas revelam que o princípio da Minimal Attachment é operativo em estruturas do tipo garden-path no PB. Os trabalhos aventados por Maia (2013) são relevantes na medida em que mostram que alguns fundamentos da TGP continuam mostrando resultados robustos em pesquisas atuais.

Os trabalhos de Carlson (2001, 2002), que fundamentam nossa proposta de pesquisa, investigaram o processamento de vários tipos de estruturas elípticas no inglês americano, tais como gapping (elipse lacunar), bare argument ellipsis (elipse do argumento nulo), replacive (elipse de "correção") e comparative (elipse de estrutura comparativa). Duas questões nortearam os trabalhos da pesquisadora: o primeiro questionamento indaga se as sentenças com elipse são processadas com mecanismos de parsing específicos ou se são processadas usando os mesmos mecanismos empregados no processamento de sentenças sem elipse; o segundo questionamento diz respeito ao paralelismo, se este influencia o processamento das estruturas elípticas e, se sim, quais características seriam mais influentes. Como nossa pesquisa tem como foco apenas a estrutura gapping em comparação com a estrutura nongapping, descreveremos aqui apenas os resultados encontrados por Carlson para essas estruturas. A autora investigou os seguintes tipos de sentenças:

(5) Alice assa bolos para turistas e Caroline para sua família.

(6) Alice assa bolos para turistas e brownies para sua família.

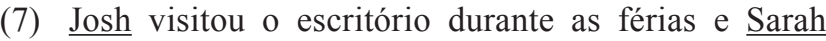
durante a semana.

(8) Josh visitou Marjorie durante as férias e Sarah durante a semana.

(9) Dan impressionou os jurados com seu talento e $\underline{\text { James }}$ com sua musicalidade.

(Adaptado de CARLSON, 2002, p. 29)

As sentenças (5) e (6), que já foram apresentadas anteriormente, só podem ser interpretadas como gapping e nongapping, respectivamente, pois verbos do tipo assar geralmente ocorrem com sujeito animado [+humano] e com objeto inanimado [-humano]. Dessa forma, a sentença (5) é mais adequada com uma interpretação gapping, pois Caroline é mais plausível como sujeito do 
verbo assar, por ser um DP animado e [+humano], do que seu objeto. Já a sentença (6) é mais adequada como nongapping, uma vez que brownies é um DP inanimado [-humano], do que como sujeito.

As sentenças (7), (8) e (9), por outro lado, apresentam um DP ambíguo após a conjunção coordenativa, conferindo a possibilidade de interpretação dupla, gapping ou nongapping. Verbos do tipo visitar podem ter como objeto constituintes animados [+humano] ou inanimados [-humano]. Na sentença (7), o DP Sarah é plausível tanto como sujeito da segunda oração (Sara visitou o escritório durante a semana) quanto como objeto coordenado (Josh visitou Sarah durante a semana). De acordo com a HP, a sentença em (7) tenderia a ser interpretada como gapping, uma vez que o DP Sarah é mais paralelo em relação ao sujeito Josh da primeira oração, pois há paralelismo de animacidade e forma entre os dois DPs. Já na sentença (8), o DP Sarah é paralelo em animacidade e forma tanto ao sujeito Josh quanto ao objeto Marjorie. Portanto, o DP Sarah é plausível tanto como sujeito da segunda oração (Sara visitou Marjorie durante a semana) quanto como objeto coordenado (Josh visitou Sarah durante a semana). No caso da sentença (9), verbos como impressionar podem ter sujeitos e objetos animados [+humanos]. Dessa forma, a sentença (9) também pode ter uma interpretação gapping ou nongapping, já que o DP Dan é paralelo em animacidade tanto com o sujeito James quanto com o objeto jurados.

No que tange ao processamento dessas estruturas, Carlson aponta que como há poucas informações lexicais e sintáticas disponíveis para guiar a estruturação de orações gapping, informações adicionais, como o paralelismo de informações prosódicas (acentos tonais, variação de pitch) e o paralelismo de informações semânticas (animacidade, gênero, número, entre outras) entre DPs das duas orações, podem influenciar as preferências interpretativas em relação ao DP com dupla interpretação. Segundo ela, estudos acerca do processamento linguístico indicam que, mesmo em coordenadas sem elipse, o processamento da segunda oração é mais fácil se esta apresentar algum tipo de paralelismo com a primeira oração. Dessa forma, ela afirma que o paralelismo pode ser um fator importante no processamento de sentenças gapping.

Por outro lado, ela também chama a atenção para o fato de que o paralelismo pode não determinar as preferências interpretativas dos falantes. É possível que os falantes manifestem preferência por uma estrutura mais simples, em consonância com o princípio de Minimal Attachment da TGP (FRAZIER, 1979).

\section{Hipótese da Estrutura Simples}

De acordo com a Hipótese da Estrutura Simples, a análise sintática mais simples de um input, quando gramatical, é preferida (CARLSON, 2002). No caso das sentenças ambíguas (7), (8) e (9), é possível que o falante prefira interpretá-la sempre como uma sentença coordenada de objeto (nongapping), já que essa estrutura envolve menos nós sintáticos do que a estrutura gapping.

A pesquisadora conduziu diferentes tipos de tarefas experimentais dos tipos on-line e off-line, com a finalidade de avaliar a influência tanto do paralelismo lexical quanto do paralelismo prosódico no processamento dessas estruturas. De um modo geral, os resultados revelam que o paralelismo prosódico e o lexical, de fato, influenciam a interpretação das estruturas gapping, entretanto, há uma preferência por parte dos falantes americanos pela estrutura mais simples, a nongapping. Portanto, os resultados de Carlson $(2001,2002)$ estão em consonância com a Hipótese da Estrutura Simples.

Recentemente, Carlson (2015) investigou como a marcação do foco sintático, através do emprego de clivagem, e a marcação de foco prosódico, através da alocação de acentos de pitch, podem influenciar a resolução de ambiguidades em sentenças elípticas do tipo replacive: It was Shirley who counseled Naomi during the flight, not Donna" (Foi Shirley quem aconselhou Naomi durante o voo, não Donna). Esse tipo de sentença contém um DP ambíguo, Naomi, depois da partícula de negação (not) que pode ser interpretado como sujeito da oração elidida ou objeto coordenado da oração antecedente. Além do foco, a pesquisadora também levou em conta o paralelismo de informações lexicais entre DPs.

As sentenças elípticas, por serem sensíveis a marcação de foco e por serem geralmente ambíguas, são ideais para se examinar qual a influência da alocação de acentos de pitch e de outros indicadores do foco no processamento (CARLSON, 2015:66). As teorias sobre resolução de ambiguidades em sentenças com elipse costumam utilizar a marcação do foco na oração antecedente para ajudar na recuperação do significado do material elidido. Os resultados de trabalhos anteriores de Carlson e de outros autores apontam que o foco é um fator importante na resolução de ambiguidades em sentenças elípticas, porém, ele não determina totalmente a interpretação delas.

A autora conduziu dois experimentos, um selfpaced reading e um experimento de escuta de sentenças. Descreveremos aqui apenas os resultados da tarefa de self-paced reading que é de particular interesse para nossa pesquisa. No experimento de self-paced, Carlson testou o foco sintático por meio da estrutura clivada e o paralelismo lexical entre DPs. As sentenças apresentavam ora a clivagem do sujeito, ora a clivagem do objeto da primeira oração. Quanto ao paralelismo, o DP ambíguo (Donna) era ora paralelo com o sujeito, ora com o objeto 
da primeira oração. Ao cruzar esses dois fatores, ela obteve quatro condições:

(10) Sujeito Clivado + Sujeito Paralelo: Foi Shirley que aconselhou um cliente durante o voo, não Donna, incrivelmente.

(11) Sujeito Clivado + Objeto Paralelo: Foi um cliente que aconselhou Shirley durante o voo, não Donna, incrivelmente.

(12) Objeto Clivado + Objeto Paralelo: Foi um cliente que Shirley aconselhou durante o voo, não Donna, incrivelmente.

(13) Objeto Clivado + Sujeito Paralelo: Foi Shirley que um cliente aconselhou durante o voo, não Donna, incrivelmente.

(Adaptado de CARLSON, 2015, p. 68)

Os resultados revelaram que tanto a clivagem quanto o paralelismo foram fatores influentes no processamento das sentenças elípticas, pois os informantes demoravam mais tempo na leitura das sentenças em que havia uma incongruência entre o elemento clivado e o DP com paralelismo semântico.

$\mathrm{Na}$ próxima seção, relatamos as atividades experimentais que foram conduzidas em nossa pesquisa, bem como os resultados encontrados em cada uma delas.

\section{Experimento 1: Raqueamento das Completações}

Este experimento consistiu em um questionário escrito que objetivou verificar quais são as preferências interpretativas de falantes nativos do $\mathrm{PB}$ na completação das sentenças coordenadas em estudo.

\subsection{Participantes}

Participaram desta atividade 30 falantes nativos do PB (17 do sexo feminino e 13 do sexo masculino), alunos dos períodos iniciais dos cursos de Artes e Design e Bacharelado Interdisciplinar em Ciências Humanas, da UFJF. Todos os participantes responderam ao mesmo modelo de questionário.

\subsection{Materiais}

Todos os itens experimentais apresentam o início de uma sentença coordenada, que contém em sua estrutura um DP sujeito, um verbo, um DP com função de objeto direto, um PP com a função de adjunto, e a conjunção coordenativa 'e', como em:

(14) [Ricardo] [plantou] [rosas] [na varanda] [e] ... $\mathrm{DP}_{\text {sujeito }} \mathrm{V} \quad \mathrm{DP}_{\text {objeto }} \mathrm{PP}$ conj.
Elaboramos três tipos de opções para completar o restante desta sentença coordenada. O primeiro tipo de completação sempre contém em sua estrutura um DP que pode funcionar como objeto coordenado e um PP adjunto; nomeamos essa opção como condição "coordenada de objeto" (nongapping). O segundo tipo de completação sempre contém em sua estrutura um DP que pode funcionar como sujeito de uma sentença elíptica e um PP adjunto; nomeamos essa opção de condição "coordenada de sujeito" (gapping). A terceira opção sempre contém uma nova sentença sem elipse, com diferentes tipos de estruturas; nomeamos de condição "coordenada sem elipse". Essa última condição serviu de controle, para que os participantes não percebessem o objetivo do estudo e também para que não tivessem que escolher apenas entre uma sentença gapping ou uma sentença nongapping.

Dessa forma, o questionário foi construído a partir de três condições experimentais, ilustradas com os exemplos abaixo (os colchetes trazem as completações):

(15) Coordenada de objeto:

Alice assou bolos para as amigas e

[biscoitos para sua prima].

(16) Coordenada de sujeito:

Alice assou bolos para as amigas e

[Camila para sua prima].

(17) Coordenada sem elipse:

Alice assou bolos para as amigas e [o forno parou de funcionar].

De acordo com o princípio Minimal Attachment, esperávamos que a opção de coordenada de objeto fosse mais escolhida como primeira opção de completação do que as estruturas da condição coordenada de sujeito. $\mathrm{O}$ design experimental do questionário foi elaborado com 14 itens experimentais, que apresentavam as versões coordenada de objeto, coordenada de sujeito e coordenada sem elipse. Além dos estímulos experimentais, elaboramos 21 sentenças distratoras e 3 exemplos para ilustrar a tarefa. Os itens foram distribuídos no questionário de forma alternada, de modo que um item experimental fosse sempre precedido e sucedido por uma sentença distratora. As opções de completação também foram randomizadas para evitar o efeito de primeira aparição.

\subsection{Procedimentos e ferramentas}

O questionário foi impresso em folhas de papel ofício tamanho A4, na orientação retrato. Distribuímos os questionários para os participantes e pedimos a eles que lessem as instruções sobre como realizar a tarefa. Dissemos também que caso houvesse alguma dúvida que nos perguntassem antes de começar a tarefa. 
As instruções indicavam que o participante, em um primeiro momento, leria o início de uma sentença e depois três opções que poderiam completar o restante da sentença. Em seguida, era pedido que ele classificasse essas opções de acordo com a sua preferência por elas, ordenando-as em 1a $2^{\underline{a}}$ e 3 a opção. Ele deveria classificar em 1을 lugar a opção que julgasse ser a melhor na completação da sentença; em $2^{\circ}$ lugar, deveria classificar a segunda melhor opção para completar a sentença; e em $3^{\circ}$ lugar, a opção que julgasse ser a terceira melhor. As instruções também sinalizavam que, caso o participante julgasse alguma das opções como inapropriada para a completação, ele poderia marcá-la com um X, ou seja, havia a possibilidade de rejeitar as estruturas de completação em teste. Depois da seção de instruções, apareciam três exemplos para ilustrar o que era esperado dos participantes na realização da tarefa.

Apresentamos abaixo um exemplo de um dos itens experimentais do questionário, respondido por um dos informantes, a título de ilustração:

\begin{tabular}{|l|l|}
\hline 6. Ricardo plantou rosas na varanda e... & Classificação \\
\hline a) Marcelo no canteiro. & $x$ \\
\hline b) o vaso caiu no chão. & $2^{2}$ \\
\hline c) orquídeas no canteiro. & $J^{2}$ \\
\hline
\end{tabular}

Figura 1. Exemplo de item experimental do questionário

Os participantes podiam reler as sentenças quantas vezes julgassem necessário. Eles levaram, em média, 25 minutos para completar todo o questionário.

\subsection{Resultados e Discussão}

Avaliamos as escolhas de completação das 14 sentenças experimentais e obtivemos um total de 420 sentenças ranqueadas, uma vez que que cada item experimental foi avaliado 30 vezes (número de participantes na tarefa). Apresentamos abaixo um gráfico com o ranking das escolhas de completação em porcentagens:

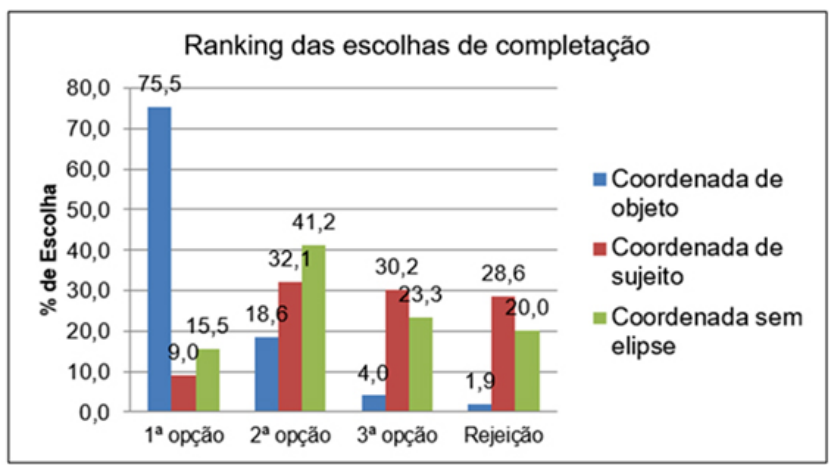

Gráfico 1. Ranking das escolhas de completação em porcentagem (\%)
A opção de completação coordenada de objeto (representada em azul, no Gráfico 1) foi a mais escolhida como primeira opção, $75,5 \%$ das vezes, e também foi a que apresentou a menor taxa de rejeição, apenas 1,9\%.

A opção de completação coordenada de sujeito (representada em vermelho, no Gráfico 1) foi a menos escolhida como primeira opção, apenas $9 \%$ das vezes e foi a opção que apresentou a maior taxa de rejeição, $28,6 \%$ das vezes.

A opção de completação coordenada sem elipse (representada em verde no Gráfico 1) foi a mais escolhida como segunda opção, $41,2 \%$ das vezes. $\mathrm{Na}$ primeira e terceira opções, foi a segunda mais escolhida, apresentando, respectivamente, as taxas $15,5 \%$ e $23,3 \%$. Também foi a segunda mais rejeitada, $20 \%$ das vezes.

Abaixo apresentamos um gráfico simplificado com as completações mais escolhidas por ordem de opção dos participantes.

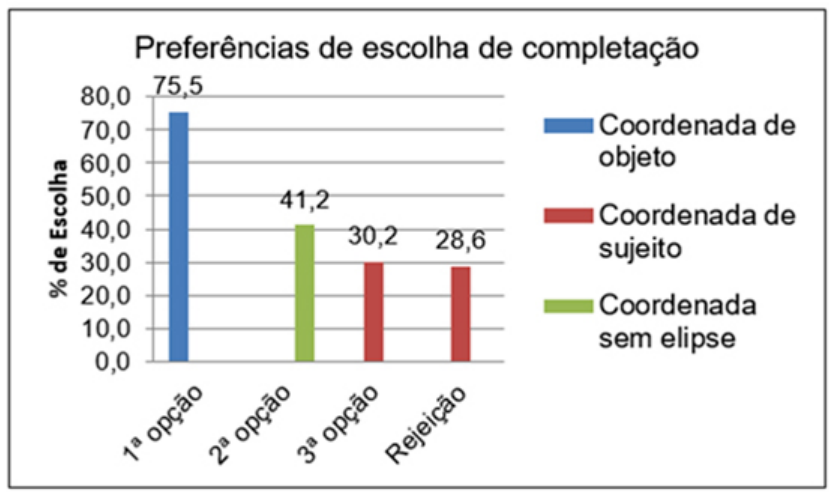

Gráfico 2. Preferências de escolha de completação por ordem de opção dos participantes, em porcentagem (\%)

Os resultados encontrados nesta tarefa off-line parecem corroborar os postulados da TGP, sobretudo o princípio Minimal Attachment. Os participantes preferiram, em sua maioria $(75,5 \%)$, a completação com uma estrutura de objetos coordenados. Essa estrutura foi preferida, inclusive, em relação à completação por uma segunda oração coordenada sem elipse. Os resultados parecem apontar para uma maior simplicidade estrutural da ligação entre objetos coordenados pela conjunção coordenativa "e". Já a estrutura coordenada de sujeito, mesmo com as pistas de paralelismo semântico entre os DPs na posição de sujeito, foi escolhida como a última opção de completação pelos participantes $(30,2 \%$ na 3a opção) e foi a estrutura mais rejeitada $-28,6 \%$ de rejeição contra $20 \%$ das coordenadas sem elipse e $1,9 \%$ das coordenadas de objeto (Gráfico 1).

No entanto, os resultados aqui apresentados dizem respeito às preferências interpretativas dos participantes, 
mas não nos permitem afirmar nada sobre o processamento on-line dessas estruturas. Para que pudéssemos avaliar as preferências de aposição on-line dos participantes para as estruturas gapping e nongapping do $\mathrm{PB}$, realizamos dois testes de self-paced reading que serão descritos a seguir.

\section{Experimento 2: Self-paced reading - DP como segmento crítico}

Neste experimento, objetivamos verificar, de forma on-line, se falantes do PB processam estruturas coordenadas de sujeito (gapping) e estruturas coordenadas de objeto (nongapping) de forma semelhante ou se há diferenças de processamento entre elas. Elaboramos a tarefa com o paradigma experimental self-paced reading (RAYNER; CLIFTON, 2002), em português, leitura automonitorada, que consiste em apresentar material linguístico por escrito de forma segmentada e medir o tempo de reação gasto pelos participantes na leitura de cada segmento. A leitura do material é controlada pelo participante por meio do acionamento de um botão. Utilizamos o self-paced do tipo cumulativo, ou seja, o material lido pelo informante era mantido na tela até que ele terminasse de ler toda a sentença.

\subsection{Participantes}

Participaram desta tarefa 20 falantes nativos do PB (10 do sexo feminino e 10 do sexo masculino), alunos dos períodos iniciais dos cursos de Artes e Design e Bacharelado Interdisciplinar em Ciências Humanas, da UFJF. Para a realização da tarefa, estes participantes foram distribuídos aleatoriamente e igualmente em dois grupos.

\subsection{Materiais}

As sentenças experimentais utilizadas neste experimento são as mesmas que foram utilizadas no experimento anterior, com a diferença de que nesta tarefa não consideramos as coordenadas sem elipse. Portanto, esta tarefa foi elaborada a partir de duas condições experimentais, ilustradas com os exemplos abaixo, sendo que as barras representam os pontos de segmentação:

\section{(18) Coordenada de objeto (nongapping):}

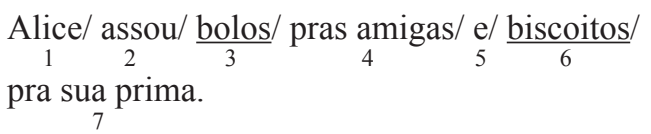

(19) Coordenada de sujeito (gapping):

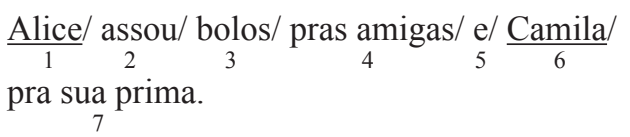

Na condição coordenada de objeto, o DP biscoitos é o segmento crítico da sentença, ou seja, é o ponto no qual o participante poderá identificar que há dois objetos coordenados na sentença. No caso da condição coordenada de sujeito, o DP Camila é o segmento crítico da sentença, ou seja, é o ponto no qual o participante poderá identificar que há duas orações coordenadas.

A nossa hipótese é a de que o processamento de sentenças com a estrutura coordenada de objeto, com base princípio de Minimal Attachment (FRAZIER, 1979) e nos resultados do experimento anterior, é menos custoso do que o processamento de sentenças com a estrutura coordenada de sujeito. Dessa forma, se o processamento de sentenças com a estrutura coordenada de objeto for menos custoso do que o processamento de sentenças com a estrutura coordenada de sujeito, o tempo de reação (TR) será menor na leitura dos DPs da condição nongapping. Por outro lado, se as duas estruturas forem igualmente naturais para os falantes, não haverá diferença de TR significativa entre as duas condições.

Durante a tarefa, cada participante teve acesso a 14 sentenças experimentais, sendo 7 de cada condição; 21 sentenças distratoras e 4 sentenças da fase de treinamento. Os DPs que compunham o segmento crítico foram controlados em relação ao tamanho, todos apresentavam 3 sílabas.

\subsection{Procedimentos e ferramentas}

O experimento foi apresentado no software DMDx (FORSTER; FORSTER, 2002) em um laptop. A atividade foi conduzida em uma sala silenciosa. Com relação aos procedimentos, em um primeiro momento, líamos as instruções junto com o participante e depois fazíamos um treinamento com 4 sentenças, para verificar se ele havia entendido como funcionava a atividade. Feito o treinamento, deixávamos a sala para que o participante fizesse a atividade sozinho. $\mathrm{O}$ experimento funcionava da seguinte forma: (i) na tela do computador, o participante lia a primeira palavra da sentença experimental; (ii) em seguida, apertava um botão predeterminado de um joystick para "chamar" os próximos fragmentos que formavam o restante da sentença; (iii) depois de ler toda a sentença, o participante acionava mais uma vez o botão do joystick e aparecia uma pergunta de compreensão do tipo sim/não, que deveria ser respondida também meio do acionamento de um botão. Cabe ressaltar que a pergunta de compreensão tinha apenas o objetivo de manter a atenção do participante na tarefa.

\subsection{Resultados e Discussão}

O programa DMDx computou o tempo de reação (TR) de todos os sete segmentos que formavam as sentenças experimentais. No entanto, consideramos na 
$\mathrm{Na}$ tarefa, cada participante visualizou 14 sentenças experimentais, 7 da condição coordenada de objeto e 7 da condição coordenada de sujeito; mais 21 sentenças distratoras e 4 sentenças da fase de treinamento. $\mathrm{O}$ fragmento crítico foi controlado em relação ao tamanho, todos apresentavam 5 sílabas.

\subsection{Resultados e Discussão}

Este experimento também foi aplicado no DMDx, que computou o TR de todos os segmentos das sentenças. Os procedimentos foram os mesmos do experimento anterior.

Analisamos apenas os valores de TR do sétimo segmento das sentenças, o qual continha o PP crítico. Desconsideramos da análise de dados os fragmentos com valores de TR abaixo de $150 \mathrm{~ms}$ e com valores acima de $4500 \mathrm{~ms}$. Os resultados indicaram que os participantes gastavam mais tempo na leitura do PP da condição coordenada de objeto, média de $863 \mathrm{~ms}$, do que na leitura do PP da condição coordenada de sujeito, média de $741 \mathrm{~ms}$, como pode ser visto no gráfico abaixo:

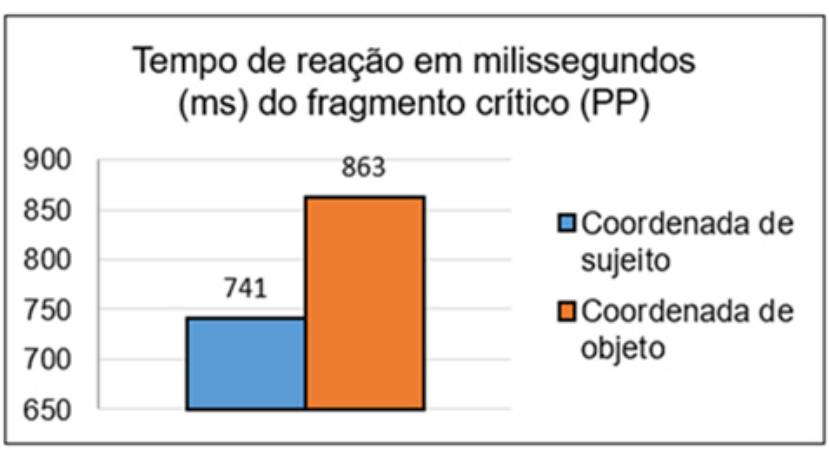

Gráfico 4. Média de TR em ms do fragmento crítico (PP) das condições Coordenada de sujeito e Coordenada de objeto

Normalizamos os valores de TR do segmento alvo com fator z-score e os submetemos aos testes de Normalidade (Kolmogorov-Smirnov) e Homogeneidade de Variância (Levene), os quais apresentaram resultados satisfatórios. Em seguida, submetemos os TRs normalizados ao teste Anova one-way, que indicou uma diferença de TR significativa entre os dois grupos (coordenada de sujeito $\times$ coordenada de objeto): $\mathrm{F}(1,261)=6,840$ e $p=0,009$.

Neste segundo teste de self-paced reading, esperávamos encontrar um tempo de reação maior nos PPs que compunham as condições de coordenada de sujeito, ou seja, um atraso na leitura do PPs que evidenciavam a elipse do VP. No entanto, os maiores tempos de reação apareceram na leitura dos PPs da condição coordenada de objeto. Avaliamos este resultado como um indício de quão custoso é para nosso processador abrir uma sentença que já foi fechada e enviada para o segundo estágio de processamento, nos termos de Frazier e Fodor (1978). Os resultados encontrados neste segundo teste de selfpaced reading parecem demonstrar que nem sempre a construção mais simples do ponto de vista estrutural (nongapping) é a mais fácil de ser processada pelo parser.

\section{Considerações finais}

$\mathrm{Na}$ tarefa off-line, os participantes preferem a coordenada de objetos (nongapping), pois do ponto de vista macroestrutural essa interpretação gera uma estrutura mais simples, seguindo os princípios Minimal Attachment e Late Closure, previstos na TGP (FRAZIER, 1979). Nas tarefas on-line, no entanto, dois fatores estruturais parecem interferir nas preferências de aposição inicial destas construções: (i) o forte paralelismo semântico (CARLSON, 2002) gerado pela característica [+ nome próprio] entre o DP que aparece após a conjunção "e" e o DP sujeito da oração principal na condição coordenada de sujeito (gapping); e (ii) o distanciamento gerado pelo PP (fragmento 4 nos exemplos 20 e 21) entre o DP objeto da oração principal e o DP inicial da segunda oração (após a conjunção "e"). Esse distanciamento parece ter provocado um efeito de Early Closure da primeira oração após o PP, fazendo com que o participante, ao se deparar com o DP [+nome próprio] das estruturas gapping fizesse uma leitura mais rápida desse DP como um sujeito de uma nova sentença do que do DP [-nome próprio] que

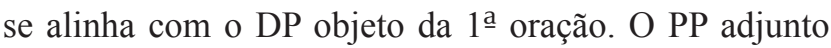
que aparece após o DP objeto da 1 a oração promove o fechamento da estrutura e, consequentemente, seu envio ao segundo estágio do processamento, como previsto por Frazier e Fodor (1978). Os resultados de tempos de reação dos nossos experimentos de self-paced reading apontam para um maior custo de processamento para o parser abrir o VP que já está fechado na primeira oração e inserir mais um DP objeto coordenado, do que para iniciar uma nova sentença, mesmo que dentro dessa nova $\mathrm{S}$ haja uma elipse, como nos casos das estruturas gapping aqui investigadas. Esse maior custo de processamento promoveu um atraso nos tempos de reação dos segmentos 6 e 7 em ambos os testes.

De modo geral, o conjunto de dados levantados nos testes off-line e on-line, empregados nesta pesquisa, aponta para a complexidade da área de processamento de frases, dentro da psicolinguística, e também para a necessidade de expansão e rechecagens de resultados dentro do campo experimental. A aplicação de diferentes tarefas experimentais, com diferentes métodos, possibilita uma visão mais ampla dos fenômenos linguísticos e, assim, uma discussão teórica mais abrangente. 


\section{Referências}

CARLSON, Katy. The Effects of Parallelism and Prosody in the Processing of Gapping Structures. Language and Speech, V. 44, n. 1, p. 1-26, 2001

CARLSON, Katy. Parallelism and Prosody in the Processing of Ellipsis Sentences. Outstanding Dissertations in Linguistics Series. New York: Routledge, 2002.

CARLSON, Katy. Clefting, Parallelism, and Focus in Ellipsis Sentences. In: FRAZIER, Lyn; GIBSON, Edward (Org.). Explicit and Implicit Prosody in Sentence Processing: Studies in Honor of Janet Dean Fodor. London: Springer, 2015. p. 63-84.

CUETOS, Fernando; MITCHELL, Don. Cross-linguistic differences in parsing: Restrictions on the use of the late closure strategy in Spanish. Cognition, v. 30, p. 73-105, 1988.

FORSTER, Jonathan; FORSTER, Kenneth. DMDX Display Software. Disponível em: <http://www.u.arizona.edu/ kforster/ dmdx/dmdx.htm>. Acesso em 12 de maio de 2017.

FRAZIER, Lyn; FODOR, Janet Dean. The Sausage Machine: A new two-stage parsing model. Cognition, n. 6, p. 1-34, 1978.
FRAZIER, Lyn. On comprehending sentences: syntactic parsing strategies. Bloomington: Indiana University Linguistics Club, 1979.

MAIA, Marcus. Linguística experimental: aferindo o curso temporal e a profundidade do processamento. Revista de Estudos da Linguagem, Belo Horizonte, v. 21, n. 1, p. 9-42, 2013.

MILHORANCE, Ludmila Pimenta Salles. Resolução de anáfora no contexto do sluicing: O caso do Português Brasileiro. 2014. 99fl. Dissertação (Mestrado em Linguística) Pontifícia Universidade Católica do Rio de Janeiro, Rio de Janeiro, 2014.

RAYNER, Keith; CLIFTON JR, Charles. Language processing. In: MEDIN, Douglas (Ed.). Steven's Handbook of Experimental Psychology: Memory and Cognitive Processes, 3. ed. New York: John Wiley and Sons Inc, 2002. Vol. 2, p. 261-316.

Recebido: 30/09/2017

Aprovado: 13/04/2018

Contato:

Andressa Christine Oliveira da Silva <andressa_cods@yahoo.com.br> 